\title{
How Do Patients with Mental Health Diagnoses Use Online Patient Portals? An Observational Analysis from the Veterans Health Administration
}

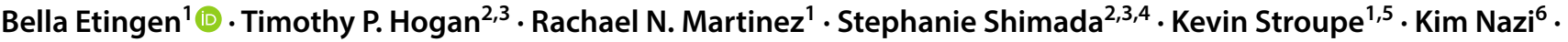 \\ Samantha L. Connolly ${ }^{2}$. Jessica Lipschitz ${ }^{7,8} \cdot$ Frances M. Weaver $^{1,5} \cdot$ Bridget Smith $^{1,9}$
}

(c) This is a U.S. Government work and not under copyright protection in the US; foreign copyright protection may apply 2019

\begin{abstract}
Online patient portals may be effective for engaging patients with mental health conditions in their own health care. This retrospective database analysis reports patient portal use among Veterans with mental health diagnoses. Unadjusted and adjusted odds of portal feature use was calculated using logistic regressions. Having experienced military sexual trauma or having an anxiety disorder, post-traumatic stress disorder, or depression were associated with increased odds of portal use; bipolar, substance use, psychotic and adjustment disorders were associated with decreased odds. Future research should examine factors that influence portal use to understand diagnosis-level differences and improve engagement with such tools.
\end{abstract}

Keywords Engagement $\cdot$ Health information technology $\cdot$ Mental health $\cdot$ Patient portals $\cdot$ Veterans

Mental health concerns such as depression, anxiety, posttraumatic stress disorder (PTSD), and substance use disorders are highly prevalent among US Veterans (Trivedi et al. 2015), and have been associated with dire consequences including elevated rates of suicide and homelessness (Metraux et al. 2013; Tsai and Rosenheck 2015; Wisco

Communicated by Micah M. Murray.

Kim Nazi was affiliated with the Department of Veterans Affairs during the time of this study, but recently retired and is now an independent consultant specializing in Sociology, Communication, and Consumer Health Informatics.

Bella Etingen

Bella.Etingen@va.gov

1 Center of Innovation for Complex Chronic Healthcare, Edward Hines Jr. VA Hospital, 5000 S. 5th Avenue (151H), Hines, IL 60141, USA

2 Center for Healthcare Organization and Implementation Research (CHOIR), Edith Nourse Rogers Memorial Veterans Hospital, Bedford, MA, USA

3 Division of Health Informatics and Implementation Science, Department of Quantitative Health Sciences, University of Massachusetts Medical School, Worcester, MA, USA

4 Department of Health Law, Policy, and Management, Boston University School of Public Health, Boston, MA, USA et al. 2014). While essential, engaging Veterans in mental health care is often challenging and met with a wide array of barriers. Engagement may be facilitated by the provision of accessible treatment options that are available remotely as well as in-person, in particular to address barriers around the stigma of in-person treatment (Berger et al. 2005). Electronic health resources for mental health, such as telehealth for service delivery, virtual asynchronous communication platforms, and other online tools can facilitate both initial and sustained engagement with mental health care (Fletcher et al. 2014; Kipping et al. 2016; Myers and Lieberman 2013).

5 Department of Public Health Sciences, Loyola University Stritch School of Medicine, Maywood, IL, USA

6 Veterans and Consumers Health Informatics Office, Office of Connected Care, Veterans Health Administration, US Department of Veterans Affairs, Coxsackie, NY, USA

7 Department of Psychiatry, Brigham and Women's Hospital, Boston, MA, USA

8 Harvard Medical School, Boston, MA, USA

9 Center for Healthcare Studies, Institute of Public Health and Medicine, Northwestern University Feinberg School of Medicine, Chicago, IL, USA 
Online patient portals linked or "tethered" to electronic health records (EHRs) offer access to personal health information and the ability to conduct transactions with a healthcare system. Portals are a potentially beneficial tool for improving patient engagement, healthcare experiences, and outcomes (Otte-Trojel et al. 2014). Within the context of care for physiological conditions, patient portals have been associated with positive outcomes such as improved communication, self-management of conditions, more appropriate healthcare use, increased adherence to medications, and improved satisfaction (Kruse et al. 2015; Lau et al. 2014; Sarkar et al. 2014; Wade-Vuturo et al. 2013).

Within the United States (US), the Department of Veterans Affairs (VA) healthcare system provides a comprehensive array of services to eligible US military Veterans who choose to utilize them. The VA system of care is comprised of approximately 1250 nationally-dispersed facilities (medical centers and outpatient clinics) offering inpatient, outpatient, home and community-based services to more than 9 million patients across their lifespan (US Department of Veterans Affairs [VA] 2019a, b). Eligibility for VA care is determined based on a number of criteria, first and foremost of which is US military service (VA 2018a).

The VA introduced its tethered online patient portal, My HealtheVet (VA 2018b), in 2003 and has continued to add new content and features to the system in the ensuing years. The My HealtheVet portal currently offers various features including: online prescription refills, asynchronous secure messaging with healthcare team members, viewing appointments and health record data such as lab/test results, health education resources, information about VA benefits, the ability to input and track personal health information, and the ability to access and download one's health record, including clinical progress notes, via the 'Blue Button' (VA, 2018b). Of note, one of the potential benefits of the Blue Button is that Veterans who receive both VA and community-based care can use it to share their health information with non-VA healthcare provider(s) (Klein et al. 2015).

The My HealtheVet system employs a tiered access model. Visitors to the portal can access some of its features and can also self-register for a basic account to enter personal health information and access various health education resources. Those patients who create a basic account and are matched by the system through a Master Veteran Index are automatically upgraded to an advanced account which offers access to more features. VA patients who also complete a one-time identity authentication process either inperson or online are further upgraded to a premium account which offers access to all My HealtheVet portal features. Table 1 presents the features that were available through $\mathrm{My}$ HealtheVet during our study period (fiscal year (FY) 2013) and their associated level of access. As described below, the analysis reported in this paper focuses on a core subset of these features intended to support interaction between Veterans and the VA healthcare system (see italicized text in Table 1). There are currently over 4.3 million registered My HealtheVet users, and over 2.6 million have been identityauthenticated (VA 2018c) and have a premium account.

Patient portals such as My HealtheVet have the potential to be highly valuable in the context of mental healthcare delivery. The health information that patients share through a portal can be useful for care delivery and coordination, and portal communication features offer an accessible way for patients to report to their providers that they are experiencing mental health concerns such as depression (Wuerdeman et al. 2005), both in terms of symptom onset or changes in symptomology or symptom severity. My HealtheVet is unique in offering patients online access to their clinical progress notes (VA Notes), including those associated with mental health treatment (Denneson et al. 2017). Early studies revealed some ambivalence among VA mental health clinicians regarding patient access to clinical notes in the context of mental health care (Dobscha et al. 2016), although studies with VA patients have suggested that thoughtfullyconstructed clinical notes could be a tool to further foster patient trust (Cromer et al. 2017).

My HealtheVet and other patient portals also provide opportunities for patients to engage with their healthcare management, through features such as online appointment scheduling and viewing upcoming appointments (which may improve appointment attendance) and medication refills (which may facilitate medication adherence). Literature suggests that patients, including those with mental health concerns such as depression and anxiety, want to use the various features that many patient portals now offer (Albert et al. 2015; Delbanco et al. 2010).

Patient portals can serve as an essential resource in mental healthcare delivery by increasing patient engagement and access, and potentially reducing stigma associated with treatment seeking. However, little is known about patient portal use among individuals with mental health concerns. An earlier analysis of My HealtheVet use in 2012 showed that adoption and use of the portal varied by patient diagnosis, and that some mental health diagnoses were associated with higher rates of adoption (Shimada et al. 2014).

Since that time, many new features have been added to the My HealtheVet portal, which may have changed rates of adoption (Nazi et al. 2018). Some of these new features, such as VA Notes and the ability to view other information from the VA's EHR, may be especially meaningful for patients with mental health diagnoses, although few studies to date have evaluated the relationship between mental health diagnosis and use of specific My Healthe Vet features. For these reasons, the objective of this analysis was to examine (1) the extent to which Veterans with mental health diagnoses use VA's My HealtheVet portal, and (2) how use of portal 
Table 1 My HealtheVet patient portal features available at the time of the study ${ }^{\mathrm{a}}$

Tiered-access model based on account type: $\mathrm{B}=$ basic $\mathrm{A}=$ advanced $\mathrm{P}=$ premium

Communication

Secure messaging: exchange secure electronic messages with healthcare team members for non-urgent needs

Appointments

Appointments: view upcoming appointments at VA facilities

Access to medical record data

Blue button: download VA medical record information ${ }^{\mathrm{b}}$, as well as self-entered and military service information, and the VA Health Summary

VA notes $^{\mathrm{c}}$ : download clinical progress notes, including mental health notes, written by VA healthcare providers

Pharmacy

Refill VA prescriptions: request prescription refills; view records of prescriptions

Prescription history: view a record of all VA prescriptions

Self-entered medications: record the name, start/end date, prescription number, and dosage for medications, over-the-counter drugs, herbals and supplements

Get Care

Caregivers: store and maintain information pertaining to caregivers and providers

Treatment facilities: find VA facilities and record those where care was received

My coverage: store and maintain information pertaining to health insurance

Health calendar: note appointments and events, set reminders and to-do lists

Wellness reminders: view customized reminders for preventative care and screens

Research health

Search collections of evidence-based health information including healthy living centers, mental health resources, and online medical databases

Track health

Vitals: record and track multiple vital signs (e.g., blood pressure, heart rate, cholesterol)

Labs \& tests: view, download, and print VA lab and test results

Self-entered tests: record tests by name, date, location, provider's name, results, and add other comments

Health history: record important health history information and events

Journals: record food intake to monitor diet and weight; track exercise routines

My Healthe Vet community

Access information relevant to the Veteran community, including VA news and announcements, volunteer opportunities, VA

benefits, My HealtheVet newsletter, and other health information

Personal information

Store and maintain contact information including emergency contacts. Manage account profile, passwords, preferences, and options

${ }^{a}$ Italics indicate core portal features that were included in our analysis; features presented without italics were available at the time of this analysis but not included as core features

${ }^{\mathrm{b}}$ Inclusion of VA medical record information as part of Blue Button downloads requires a Premium account

${ }^{\mathrm{c}}$ Feature added to the My HealtheVet portal in January 2013

features varies across Veterans with different mental health diagnoses.

\section{Methods}

\section{Study Design}

Data were collected as part of a larger study, which was comprised of a retrospective database analysis examining My HealtheVet use among approximately 3.5 million
Veterans receiving VA health care (see Fig. 1, cohort derivation diagram), including impacts on VA healthcare use, feature use, dual use in which Veterans also receive care in community settings, and cost. The focus of this analysis was use of My HealtheVet (in general and in terms of specific core features) among the Veterans from that overall sample with various mental health diagnoses. 


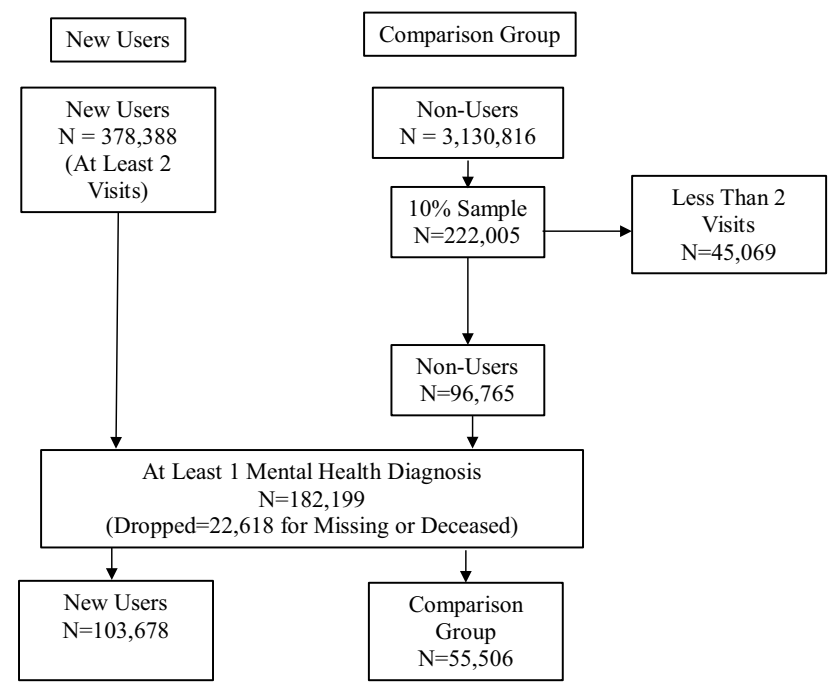

Fig. 1 Sample derivation diagram

\section{Participants}

Starting with the overall sample for the larger study noted above (see Fig. 1), we selected Veterans with a mental health diagnosis (defined as having at least two instances of the diagnosis documented in the VA administrative records during outpatient encounters or one instance documented in the VA administrative records during an inpatient encounter) in the year prior to the index date. The index date was defined as the first use of My HealtheVet in FY2013 for the My Healthe Vet users (with no history of use prior to FY2013) and the first day of that fiscal year (Oct. 1, 2012) for the comparison group. ICD-9 codes used to define each mental health diagnosis (except for military sexual trauma (MST)) were based on definitions detailed in Carlson et al. (2010) (see Table 2). A Veteran was classified as having experienced MST if they had a positive MST indicator noted in VA administrative records in the year prior to their index date. We then sampled $10 \%$ of all Veterans who received healthcare in the VA in FY2013 but had never used My Healthe Vet, and excluded Veterans with less than two encounters before or after the index date.

Veterans who were deceased, aged younger than 18 or older than 104, and those with missing data on variables included as covariates in adjusted models (distance to nearest VA; region of residence; urbanicity of residence; enrollment; income) were excluded from the sample. The final analytic sample for this study was composed of 159,581 Veterans who use VA healthcare services with at least one mental health diagnosis.

\section{Measures and Data Sources}

Demographics Information about Veteran characteristics were obtained from the Veterans Health Administration Medical SAS Databases, which contain data extracted from patient electronic medical records (VA Information Resource Center [VIReC] 2011a, b), and included gender, age, race, ethnicity, and US geographic region of residence (i.e., midwest, northeast, south, west, other). The distance between the nearest VA facility to the Veteran and the zip code associated with the Veteran's address were used to determine the distance to their nearest VA. A Veteran's VA enrollment group, a classification system used to determine copayment for VA services based on disability rating, income and other factors (e.g., prisoner of war (POW) status), was determined using the VA Enrollment file (VIReC 2013). A Veteran's estimated income bracket was determined using census data detailing the median household income for the zip code associated with their residence (Thomas et al. 2006); this zip code was also used to determine the urbanicity of where the Veteran lived (Abrams et al. 2010). Overall health status was estimated through the CMS Hierarchical Condition Category risk-adjustment model for community-dwelling populations (Morgan et al. 2009; Pope et al. 2004).

My HealtheVet Registration and Use Registration for My Healthe Vet and use of core portal features (medication refill, secure messaging, Blue Button, appointment view) was calculated for the Veterans in our sample within the year following their respective index date. Veterans were
Table 2 Mental health diagnoses and corresponding ICD-9 Codes ${ }^{\mathrm{a}}$

Depressive disorders
Post-traumatic stress disorder (PTSD)
Substance use disorders
Anxiety disorders (not including PTSD)
Psychotic disorders (including schizophrenia)
Adjustment disorders/stress reactions
Bipolar disorders
Military Sexual Trauma (MST)

296.20-296.36, 296.50-296.55, 296.90, 300.4, 311 309.81

291.x, 292.x, 303.xx, 304.xx, 305.xx [excluding 305.1, tobacco use disorder] 300.0x, 300.2x, 300.3 295.x, 297.x, 298.x. 308.x, 309.x [excluding 309.81, PTSD] 296.00-296.16, 296.4x, 296.56, 296.6x, 296.8x MST Indicator (Recorded in VA Administrative Data)

${ }^{\text {a }}$ ICD-9 codes used to define each disorder (except for MST) were based on definitions detailed in Carlson et al. (2010) 
considered to have used a portal feature if they had any use of that feature in this time-frame (as opposed to no use). Secure messaging use included read messages and/or sent messages. Blue Button use included any use of the feature.

\section{Statistical Analyses}

To account for the random sample of non-users, all data for non-users was weighted and all statistics were calculated to reflect the weighting. Descriptive statistics were used to determine the proportion of Veterans with each mental health diagnosis (and multimorbidity of mental health diagnoses), and characterize the demographics of the sample along with the proportion of the sample who registered for My Healthe Vet and used each of the portal features. A series of logistic regression models were then conducted (separately for each mental health diagnosis). We used logistic regression models because the outcome variables of interest are discrete rather than continuous. In cases where there is a discrete outcome variable, modeling the outcome as a continuous variable in a linear regression model is problematic because the predicted outcomes from the model are not constrained to be between 0 and 1 (Greene 1992).

A set of unadjusted models determined the odds that a Veteran in our sample registered for a My HealtheVet account. Among the Veterans who registered, we ran models estimating the odds of having used each of the portal features. The same process was then repeated to estimate adjusted models, which controlled for the potentially confounding influence of key demographic variables (e.g., gender, age, race, ethnicity, region of residence, VA enrollment group, income, urbanicity of residence, distance to VA, community score) and multimorbidity of mental health conditions on My HealtheVet use. To test for multicollinearity, we also estimated the variance inflation factors for each variable; the results suggested that the variables in the regression were not highly correlated.

An alpha level of 0.05 was used to determine statistical significance. Statistical analyses were performed with STATA MP Version 14.2 software (StataCorp, College Station, TX). This study was approved by the Institutional Review Boards at the Edward Hines Jr. VA Hospital and Edith Nourse Rogers Memorial Veterans Hospital.

\section{Results}

\section{Sample Description}

The distribution of mental health conditions (including the proportion who had experienced MST) is presented in Table 3. Depressive disorders (52.8\%) were the most prevalent diagnosis among our sample, while the experience
Table 3 Distribution of mental health diagnoses among our sample $(\mathrm{n}=159,581)$

\begin{tabular}{ll}
\hline Diagnosis & $\begin{array}{l}\text { Percentage of } \\
\text { sample with } \\
\text { diagnosis }\end{array}$ \\
\hline Depressive disorders & 52.77 \\
Post-traumatic stress disorder (PTSD) & 33.80 \\
Substance use disorders & 26.42 \\
Anxiety disorders (not including PTSD) & 22.37 \\
Psychotic disorders (including schizophrenia) & 11.00 \\
Adjustment disorders/stress reactions & 7.50 \\
Bipolar disorders & 5.42 \\
Military sexual trauma (MST) & 1.23 \\
Multimorbidity (2 or more of the above diagno- & 42.26 \\
$\quad$ ses) & \\
\hline
\end{tabular}

of MST was the least prevalent (1.2\%). Overall, our sample was comprised predominantly of males $(93.3 \%)$ aged 60-69 years $(37.8 \%)$, who were of white race/ethnicity (73.8\%) and lived in urban settings $(63.5 \%)$. Please see Table 4 for demographics broken down by each mental health condition. Of note, $13.7 \%$ of our sample as a whole were registered My HealtheVet users.

\section{Descriptive Usage of My HealtheVet Features by Mental Health Condition}

The proportion of Veterans with each mental health diagnosis who used each My HealtheVet feature is shown in Table 5. The proportion of Veterans who had registered for My HealtheVet was highest among Veterans who had experienced MST (41.7\%) and lowest among Veterans with a psychotic disorder (7.1\%). The greatest proportion of Veterans within each diagnostic group used the medication refill function, followed by appointment view, secure messaging, and Blue Button.

\section{Odds of Usage of My HealtheVet Features by Mental Health Condition}

Results of the regression models are presented in Table 6 (unadjusted) and Table 7 (adjusted for potential confounding factors). Key findings of adjusted analyses are described below.

Adjustment Disorder Having an adjustment disorder was associated with increased odds of My Healthe Vet registration (OR 1.16; CI95 1.11-1.21), but decreased odds of use of the medication refill function (OR .86; CI95 .82-.90).

Anxiety Disorder Having an anxiety disorder was associated with increased odds of My HealtheVet registration (OR 1.15; CI95 1.11-1.18), and increased odds of using the following portal features: medication refill (OR 1.05; CI95 


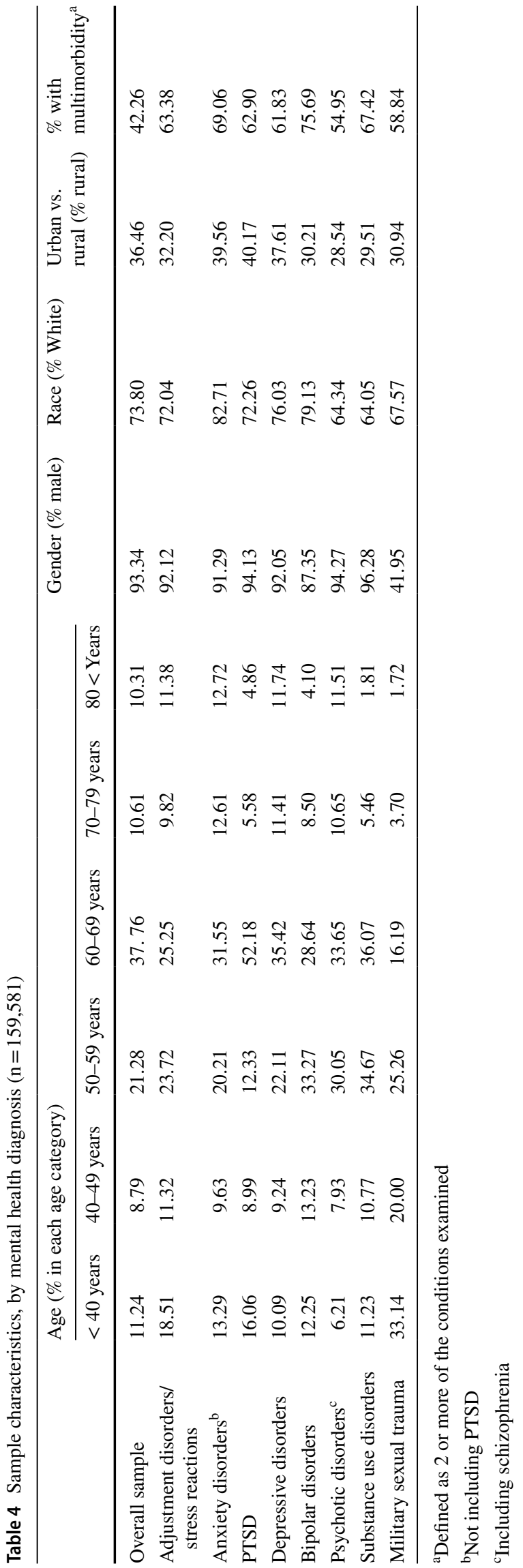

1.02-1.09); secure messaging (OR 1.05; CI95 1.02-1.09); Blue Button (OR 1.05; CI95 1.01-1.10).

PTSD Having PTSD was associated with increased odds of My Healthe Vet registration (OR 1.25; CI95 1.22-1.29), and increased odds of using the following portal features: appointment view (OR 1.08; CI95 1.05-1.12); Blue Button (OR 1.14; CI95 1.09-1.19).

Depressive Disorder Having a depressive disorder was associated with increased odds of My Healthe Vet registration (OR 1.23; CI95 1.20-1.27), and increased odds of using the following portal features: medication refill (OR 1.17; CI95 1.14-1.21); appointment view (OR 1.06; CI95 1.03-1.09); secure messaging (OR 1.05; CI95 1.02-1.09).

Bipolar Disorder Having bipolar disorder was associated with decreased odds of My HealtheVet registration (OR .79; CI95 .75-.83), and decreased odds of using the following portal features: medication refill (OR .87; CI95 .82-.92); appointment view (OR .91; CI95 .85-.97); Blue Button (OR .86; CI95 .79-.93).

Psychotic Disorder Having a psychotic disorder was associated with decreased odds of My HealtheVet registration (OR .47; CI95 .46-.49), and decreased odds of use of each portal feature: medication refill (OR .83; CI95 .78-.88); appointment view (OR .74; CI95 .70-.79); secure messaging (OR .82; CI95 .77-.88); Blue Button (OR .68; CI95 $.62-.75)$.

Substance Use Disorder Having a substance use disorder was associated with decreased odds of My HealtheVet registration (OR .71; CI95 .69-.73), and decreased odds of use of each portal feature: medication refill (OR .76; CI95 .73-.78); appointment view (OR .88; CI95 .85-.91); secure messaging (OR .85; CI95 .81-.88); Blue Button (OR .94; CI95 .89-.98).

MST Having experienced MST was associated with increased odds of My HealtheVet registration (OR 2.52; CI95 2.27-2.80), and increased odds of use of each portal feature: medication refill (OR 1.23; CI95 1.15-1.32); appointment view (OR 1.42; CI95 1.32-1.52); secure messaging (OR 1.29; CI95 1.20-1.40); Blue Button (OR 1.39; CI95 1.27-1.53).

\section{Discussion}

To the best of our knowledge, our study is among the first to examine use of the core features of a major integrated healthcare system's patient portal among individuals with various mental health diagnoses. Notably, we found that Veterans who had experienced MST were the most likely to use each of the VA's My HealtheVet portal features included in our analysis. This may be explained in part by the high rates of psychological and physiological comorbidities observed in Veterans who have experienced MST (Hyun et al. 2009; 
Table 5 My HealtheVet adoption and use, by mental health condition

\begin{tabular}{|c|c|c|c|c|c|}
\hline [Values indicate percentages] & $\begin{array}{l}\text { Registered for } \\
\text { patient portal }\end{array}$ & $\begin{array}{l}\text { Used medication } \\
\text { refill }^{c}\end{array}$ & $\begin{array}{l}\text { Appointment } \\
\text { view }^{c}\end{array}$ & $\begin{array}{l}\text { Sent or read at least one } \\
\text { secure message }^{c}\end{array}$ & $\begin{array}{l}\text { Blue button } \\
\text { download }^{c}\end{array}$ \\
\hline Adjustment disorders/stress reactions & 17.24 & 34.89 & 28.95 & 22.18 & 12.53 \\
\hline Anxiety disorders ${ }^{\mathrm{a}}$ & 15.67 & 39.04 & 29.86 & 23.20 & 13.79 \\
\hline PTSD & 16.31 & 38.91 & 30.69 & 22.84 & 13.55 \\
\hline Depressive disorders & 14.68 & 38.25 & 29.88 & 22.59 & 12.97 \\
\hline Bipolar disorders & 13.62 & 35.47 & 28.20 & 21.83 & 11.81 \\
\hline Psychotic disorders $^{\mathrm{b}}$ & 7.10 & 30.79 & 23.75 & 18.69 & 8.77 \\
\hline Substance use disorders & 12.49 & 33.07 & 27.50 & 19.95 & 12.16 \\
\hline Military sexual trauma & 41.72 & 44.28 & 35.58 & 28.94 & 16.76 \\
\hline
\end{tabular}

${ }^{a}$ Not including PTSD

${ }^{\mathrm{b}}$ Including schizophrenia

${ }^{\mathrm{c}}$ Values represent percentages of registered patients

Table 6 Unadjusted odds of My HealtheVet adoption and use by mental health condition $(n=159,581)$

\begin{tabular}{|c|c|c|c|c|c|}
\hline $\begin{array}{l}\text { [Values indicate: OR (95\% CI) stand- } \\
\text { ard error] }\end{array}$ & Registered & Used medication refill $^{\mathrm{c}}$ & Appointment view ${ }^{c}$ & $\begin{array}{l}\text { Sent or read at least } \\
\text { one secure message }^{c}\end{array}$ & Blue button download \\
\hline \multirow[t]{3}{*}{ Adjustment disorders/stress reaction } & $1.34 * * *$ & $.90 * * *$ & .98 & .99 & .98 \\
\hline & $(1.29-1.40)$ & $(.86-.94)$ & $(.94-1.03)$ & $(.94-1.04)$ & $(.92-1.04)$ \\
\hline & .03 & .02 & .02 & .03 & .03 \\
\hline \multirow[t]{3}{*}{ Anxiety disorders ${ }^{\mathrm{a}}$} & $1.23 * * *$ & $1.12 * * *$ & $1.04 *$ & $1.07 * * *$ & $1.13 * * *$ \\
\hline & $(1.20-1.26)$ & $(1.08-1.15)$ & $(1.00-1.07)$ & $(1.04-1.11)$ & $(1.09-1.18)$ \\
\hline & .02 & .02 & .02 & .02 & .02 \\
\hline \multirow[t]{3}{*}{ PTSD } & $1.38 * * *$ & $1.14 * * *$ & $1.12 * * *$ & $1.05^{* *}$ & $1.13 * * *$ \\
\hline & $(1.35-1.41)$ & $(1.11-1.17)$ & $(1.09-1.15)$ & $(1.02-1.08)$ & $(1.09-1.17)$ \\
\hline & .02 & .01 & .02 & .02 & .02 \\
\hline \multirow[t]{3}{*}{ Depressive disorders } & $1.19 * * *$ & $1.12 * * *$ & $1.07 * * *$ & $1.04 *$ & $1.05^{*}$ \\
\hline & $(1.17-1.21)$ & $(1.09-1.15)$ & $(1.04-1.09)$ & $(1.01-1.07)$ & $(1.01-1.09)$ \\
\hline & .01 & .01 & .01 & .02 & .02 \\
\hline \multirow[t]{3}{*}{ Bipolar disorders } & .99 & $.93 * *$ & .94 & .97 & $.91 *$ \\
\hline & $(.95-1.04)$ & $(.88-.98)$ & $(.89-1.00)$ & $(.91-1.04)$ & $(.84-.99)$ \\
\hline & .02 & .03 & .03 & .03 & .04 \\
\hline \multirow[t]{3}{*}{ Psychotic disorders ${ }^{\mathrm{b}}$} & $.45^{* * *}$ & $.74 * * *$ & $.74 * * *$ & $.79 * * *$ & $.64 * * *$ \\
\hline & $(.43-.47)$ & $(.70-.79)$ & $(.70-.79)$ & $(.74-.85)$ & $(.59-.71)$ \\
\hline & .01 & .02 & .02 & .03 & .03 \\
\hline \multirow[t]{3}{*}{ Substance use disorders } & $.87 * * *$ & $.79 * * *$ & $.89 * * *$ & $.83 * * *$ & $.93 * *$ \\
\hline & $(.85-.89)$ & $(.77-.82)$ & $(.86-.92)$ & $(.80-.86)$ & $(.89-.97)$ \\
\hline & .01 & .01 & .01 & .01 & .02 \\
\hline \multirow[t]{3}{*}{ Military sexual trauma } & $4.64 * * *$ & $1.36^{* * *}$ & $1.35 * * *$ & $1.44 * * *$ & $1.40 * * *$ \\
\hline & $(4.21-5.11)$ & $(1.28-1.45)$ & $(1.26-1.44)$ & $(1.34-1.55)$ & $(1.28-1.53)$ \\
\hline & .23 & .04 & .05 & .05 & .06 \\
\hline
\end{tabular}

${ }^{*} p<0.05 ; * * p<0.01 ; * * * p<0.00$

${ }^{\mathrm{a} N o t}$ including PTSD

${ }^{\mathrm{b}}$ Including schizophrenia

${ }^{\mathrm{c}}$ Values represent calculations for registered patients 
Table 7 Adjusted odds of My HealtheVet adoption and use by mental health condition ${ }^{\mathrm{a}}(\mathrm{n}=159,581)$

\begin{tabular}{|c|c|c|c|c|c|}
\hline $\begin{array}{l}\text { [Values indicate: OR }(95 \% \mathrm{CI}) \text { stand- } \\
\text { ard error] }\end{array}$ & Registered & Used medication refill $^{\mathrm{d}}$ & Appointment view ${ }^{\mathrm{d}}$ & $\begin{array}{l}\text { Sent or read at least } \\
\text { one secure message }^{\mathrm{d}}\end{array}$ & Blue button download $^{\mathrm{d}}$ \\
\hline \multirow[t]{3}{*}{ Adjustment disorders/stress reactions } & $1.16^{* * *}$ & $.86^{* * *}$ & .98 & 1.00 & .97 \\
\hline & $(1.11-1.21)$ & $(.82-.90)$ & $(.93-1.02)$ & $(.95-1.05)$ & $(.91-1.03)$ \\
\hline & .03 & .02 & .02 & .03 & .03 \\
\hline \multirow[t]{3}{*}{ Anxiety disorders ${ }^{\mathrm{b}}$} & $1.15^{* * *}$ & $1.05^{* *}$ & 1.00 & $1.05 * *$ & $1.05^{*}$ \\
\hline & $(1.11-1.18)$ & $(1.02-1.09)$ & $(.97-1.03)$ & $(1.02-1.09)$ & $(1.01-1.10)$ \\
\hline & .02 & .02 & .02 & .02 & .02 \\
\hline \multirow[t]{3}{*}{ PTSD } & $1.25 * * *$ & 1.02 & $1.08 * * *$ & 1.02 & $1.14 * * *$ \\
\hline & $(1.22-1.29)$ & $(1.00-1.05)$ & $(1.05-1.12)$ & $(.98-1.05)$ & $(1.09-1.19)$ \\
\hline & .02 & .02 & .02 & .02 & .02 \\
\hline \multirow[t]{3}{*}{ Depressive disorders } & $1.23 * * *$ & $1.17 * * *$ & $1.06^{* * *}$ & $1.05 * *$ & 1.00 \\
\hline & $(1.20-1.27)$ & $(1.14-1.21)$ & $(1.03-1.09)$ & $(1.02-1.09)$ & $(.96-1.04)$ \\
\hline & .02 & .02 & .02 & .02 & .02 \\
\hline \multirow[t]{3}{*}{ Bipolar disorders } & $.79 * * *$ & $.87 * * *$ & $.91 * *$ & .94 & $.86^{* * *}$ \\
\hline & $(.75-.83)$ & $(.82-.92)$ & $(.85-.97)$ & $(.88-1.00)$ & $(.79-.93)$ \\
\hline & .02 & .03 & .03 & .03 & .04 \\
\hline \multirow[t]{3}{*}{ Psychotic disorders $^{\mathrm{c}}$} & $.47 * * *$ & $.83 * * *$ & $.74 * * *$ & $.82 * * *$ & $.68 * * *$ \\
\hline & $(.46-.49)$ & $(.78-.88)$ & $(.70-.79)$ & $(.77-.88)$ & $(.62-.75)$ \\
\hline & .01 & .02 & .02 & .03 & .03 \\
\hline \multirow[t]{3}{*}{ Substance use disorders } & $.71 * * *$ & $.76^{* * *}$ & $.88 * * *$ & $.85 * * *$ & $.94 * *$ \\
\hline & $(.69-.73)$ & $(.73-.78)$ & $(.85-.91)$ & $(.81-.88)$ & $(.89-.98)$ \\
\hline & .01 & .01 & .02 & .02 & .02 \\
\hline \multirow[t]{3}{*}{ Military sexual trauma } & $2.52 * * *$ & $1.23 * * *$ & $1.42 * * *$ & $1.29 * * *$ & $1.39 * * *$ \\
\hline & $(2.27-2.80)$ & $(1.15-1.32)$ & $(1.32-1.52)$ & $(1.20-1.40)$ & $(1.27-1.53)$ \\
\hline & .14 & .04 & .05 & .05 & .07 \\
\hline
\end{tabular}

$* p<0.05 ; * * p<0.01 ; * * * p<0.00$

${ }^{a}$ Controlling for veteran characteristics: gender, age, race (white and African American), ethnicity, region of residence, VA enrollment group, income, urbanicity of residence, distance to VA, community score, multimorbidity of mental health diagnoses (2 or more diagnoses)

${ }^{\mathrm{b}}$ Not including PTSD

${ }^{\mathrm{c}}$ Including schizophrenia

${ }^{\mathrm{d}}$ Values represent calculations for registered patients

Waitzkin et al. 2018; Yaeger et al. 2006), which may lead to greater healthcare use, in general, and unique care needs. Additionally, while both male and female Veterans experience it, MST is more prevalent among women Veterans; women Veterans tend to be younger than their male counterparts, and (while emerging evidence suggests this is mixed) may be more likely to be portal users in general (Goel et al. 2011; VA 2017; Wallace et al. 2016) and may also prefer to avoid VA hospitals if they are not comfortable there.

Veterans who had experienced MST were followed by those with stress and mood-related disorders (depression, anxiety disorders, and PTSD), while those with adjustment disorder, substance use disorder, bipolar disorder and psychotic disorder were the least likely to be registered My HealtheVet users and adopters of the main portal features. The differences we observed among groups align with previous studies indicating that My HealtheVet use tends to be higher among Veterans with certain mental health diagnoses (e.g., anxiety, PTSD, depression) compared to others (e.g., substance use disorders, schizophrenia) (Shimada et al. 2014).

Proportionally, the most used features in our cohort were the medication refill and appointment view functions. These findings are consistent with previous research that has reported high use of the My HealtheVet medication refill feature among a national sample of VA patients (Shimada et al. 2014). However, our findings also extend those reported by Shimada et al. (2014), in that they suggest the appointment view function (which was not available at the time that study was conducted) is a highly utilized addition to the My HealtheVet platform. As of FY 2017, Veterans can also request appointments via a new online scheduling feature, which, in time, may become another widely used My HealtheVet feature. These results are promising 
when considering the role that My HealtheVet can have in mental healthcare provision, particularly that it may be a useful mechanism to facilitate access to care, appointment attendance, and medication adherence. Further, our findings suggest that My HealtheVet features have the potential to improve healthcare processes and outcomes for Veterans with mental health diagnoses, and further highlight the importance of taking a comprehensive look at use of specific My HealtheVet features in this vulnerable population.

\section{Medication Refill}

When controlling for extraneous influences, we found that odds of use of this feature are increased and highest for Veterans who have experienced MST, and increased for those with depression and anxiety diagnoses; odds of use are decreased for those with adjustment disorder, bipolar, substance use, and psychotic disorders. This is consistent with research on adherence to psychotropic medications that indicates poor adherence among patients with psychotic disorders and bipolar disorder (Byerly et al. 2007; Sajatovic et al. 2007; Sajatovic et al. 2006; Velligan et al. 2009). It is also consistent with findings that substance use disorder is a predictor of medication non-adherence, for both psychotropic and non-psychotropic medication (Gonzalez et al. 2011; Swartz et al. 1998).

Overall, however, high rates of use for this feature indicate that it could be a useful clinical tool. Research suggests that clinicians often overestimate patients' medication adherence (Stephenson et al. 2012). By using the medication refill tool, patients offer members of their clinical team insight about the odds that they are medication adherent at any given point in time. More accurate understanding of medication adherence could pave the way for clinician-delivered (or portal-delivered) interventions to improve medication adherence or, when necessary, alter prescriptions to reduce barriers to adherence such as side effects.

\section{Secure Messaging}

Secure messaging within the My HealtheVet portal has been viewed positively by Veterans (Haun et al. 2014) and may improve health outcomes for patients with chronic conditions (Shimada et al. 2016). We found that, when controlling for extraneous influences, odds of secure messaging use are increased and highest for MST, followed by anxiety and mood-related disorders (depression), but are decreased for psychosis and substance use. The use of secure messaging systems within the field of psychiatry is rapidly increasing (Cronin et al. 2015). One randomized controlled trial found that patients were more likely to communicate psychosocial information by secure messaging than telephone (Lin et al. 2005). Additionally, clinicians report that secure messaging decreases the threshold at which patients may initiate communication with their healthcare team, which is especially important between in-person clinical encounters (Nazi 2013).

Secure messaging may be a convenient and preferable mode of communication for patients as it allows them to send messages whenever they need to, affords them the ability to craft the content of their messages carefully in a pressure-free setting, and does not require that they repeat their personal information to staff responsible for phone triage (who may be unfamiliar to them) (Haun et al. 2013). Furthermore, some patients may find it easier to disclose personal information regarding their mental health through secure messaging as opposed to by telephone or in person, as this mode of communication may feel more discreet (Lin et al. 2005). Accordingly, it is important to leverage this feature to aid in mental health care for the diagnostic cohorts who are willing to use it, and to take steps to increase use among patients with mental health conditions who could greatly benefit from this feature but are less likely to take advantage of it. For instance, providers working with patients in the diagnostic categories less likely to use secure messaging may consider engaging in motivational interviewing or other kinds of communication with these patients to encourage engagement with this feature.

\section{Blue Button Download}

By making information from their health record available for Veterans to view and print, use of the My HealtheVet Blue Button feature may facilitate Veterans who also use non-VA services in sharing the information in their VA records with their non-VA providers (Turvey et al. 2014). Literature suggests that Veterans are highly satisfied with their ability to access their health information in My HealtheVet (Nazi et al. 2013). Our data indicates that odds of Blue Button use are increased and highest for Veterans who have experienced MST, and increased for those with PTSD and anxiety, while odds of use are decreased for persons with bipolar disorder, substance use disorder, and psychotic disorders.

Proportionally, however, Blue Button was the least used feature among each of the mental health cohorts we looked at. This may be due in part to the fact that the data available via Blue Button was only significantly expanded in January 2013 (several months into our study time frame), including access to VA clinical progress notes which encompassed mental health notes. Additionally, since the completion of our study the more intuitive label of "health records" was added to the dashboard that appears on the My Healthe Vet home page to enhance Veteran navigation to the Blue Button, potentially increasing awareness and use of this portal feature. Our lack of insight into reasons for low uptake of 
this feature among our cohort indicates that further evaluation of Veteran perspectives on this feature is warranted.

\section{Appointment View}

We found that the odds of using the My HealtheVet appointment view feature are greater for Veterans with MST, PTSD and depression, and lower for those with bipolar, substance use, and psychotic disorders. A recent study by Kipping et al. (2016) found that patient portal use among individuals with "serious or persistent mental illness" resulted in decreased missed appointments and increased patient activation (Kipping et al. 2016). Taken together, these findings support the importance of future research to better understand and increase use of this feature in those with bipolar, substance use and psychotic disorders. This is especially true since mental health treatment engagement among Veterans tends to be low (Stecker et al. 2010) and appointment non-attendance has been associated with greater symptom severity, poorer social and vocational functioning, medication non-adherence, higher rates of suicide, dropout from services, and rehospitalization (Fischer et al. 2008; Killaspy et al. 2000; Mitchell and Selmes 2007).

Moreover, since the present study was completed, additional appointment management features have become available to Veterans through My HealtheVet, including the ability to receive email appointment reminders and request/ schedule appointments. Accordingly, leveraging these various appointment management capabilities supported through MHV may increase the chances that Veterans remember upcoming appointments and attend them.

\section{Implications for Care}

Tsai and Rosenheck (2012) reported that Veterans who use VA mental health services are equally likely to use My HealtheVet compared to their Veteran counterparts who receive VA care services unrelated to mental health. However, our data indicates that among Veterans with mental health concerns, some mental health conditions are associated with higher likelihood of My HealtheVet use than others. Specifically, individuals with bipolar disorder, psychotic disorders and substance use disorders have the lowest odds of registration and use of all My HealtheVet features. This is not surprising, given that management of these conditions comes with some unique challenges related to healthcare use and engagement in care (e.g., high comorbidity with homelessness, lower medication adherence, and cognitive impairment). While there may be additional barriers to $\mathrm{My}$ HealtheVet use among individuals with these conditions, our data identify where outreach efforts may be targeted to encourage these vulnerable cohorts to be more engaged in using My HealtheVet. Such efforts could also help guard against the potential for disparities in use of My HealtheVet among Veterans with mental health diagnoses. In addition, while these efforts would be among many other non-portalbased strategies, introducing these patients to My HealtheVet could increase engagement with their mental and physiological health care in general, as well as other health-related technologies (e.g., clinical video telehealth, text messaging reminders) that the VA offers. It will be important for future research to explore the specific barriers to My HealtheVet use experienced within these populations, along with additional features these individuals would prefer My HealtheVet include (e.g., email reminders about medication refills), to improve engagement with the portal.

Findings that engagement with the portal was fairly high within some diagnostic groups (i.e., depression, anxiety, PTSD, and particularly, persons who have experienced MST) supports efforts to use My HealtheVet as an outreach platform for intervention/program delivery. For instance, an RCT being conducted by Simon et al. (2016) is using secure messaging to deliver a suicide prevention intervention to individuals determined to be at-risk for suicide attempt(s). Additionally, recent evidence suggests that use of online psychoeducation may reduce shame and increase self-directed empathy (Talbot et al. 2017), which may in turn reduce mental health associated stigma.

Given that stigma is commonly noted among the top barriers to mental healthcare engagement in the Veteran population (Hoge et al. 2004), using patient portals such as My HealtheVet to deliver mental health education and facilitate care has considerable potential to minimize related stigma and improve engagement with and adherence to mental health care. For instance, My HealtheVet features can be used to develop interventions or outreach efforts to promote psychological well-being and mental healthcare engagement. This may be particularly useful among Veterans who have experienced MST or have anxiety or mood-related diagnoses, as they are more likely to access resources and tools on this platform.

\section{Limitations}

Our study used a MST indicator to identify a history of MST; however, past research has shown that this may underestimate the prevalence of MST in the Veteran population by $5 \%$ (Gundlapalli et al. 2017). Our analyses did not take into account overlap between mental health and other medical diagnoses, and as such, it may be that comorbid diagnoses are driving some of the associated portal use. Moreover, because the Veterans included in our sample were all new My HealtheVet users who first adopted use of the portal in FY13, the generalizability of our results to all Veteran users may be limited. Further, our analysis focused only on a core subset of portal features 
and is only able to represent a point in time, while the patient portal itself, along with the features and content it offers, continues to evolve, a formidable challenge noted in previously published patient portal research agendas (Nazi et al. 2010). We conceptualized feature use as any use within a specified time period; future research could examine the frequency of use to account for one-time versus repeat users. Additionally, no indicator of illness severity was available in our dataset. Evaluating the relationship between illness severity and online portal use could provide important supplemental knowledge about how and when My HealtheVet feature use is more or less likely to occur and how to leverage the platform for outreach and intervention delivery.

\section{Conclusions}

Patient portals are a valuable tool for facilitating the patient-provider connection (e.g., via secure messaging) as well as facets of mental health treatment (e.g., via medication refills). Our data suggest that this tool is most likely to be used by individuals with depression, anxiety and stress-related disorders, as well as (and maybe particularly for) those who have experienced MST. However, based on our analysis, use of patient portals and their features is also limited among patients with other diagnoses (e.g., bipolar, substance use, and psychotic disorders). As My Healthe Vet may provide a less stigmatized access option for treatment facilitation/delivery, efforts are needed to understand why engagement has been low in these groups. Such insights may clarify how best to effectively increase portal engagement in these cohorts and/or provide insights into complementary or alternative channels (e.g., clinical video telehealth or texting reminders) more acceptable to them. Such efforts may reduce potential disparities that might arise from differences in portal use by persons with different mental health conditions.

\footnotetext{
Acknowledgements This study was supported by the Department of Veterans Affairs, Office of Research and Development, Health Services Research and Development Service (IIR 14-041). The views expressed in this article are those of the authors and do not necessarily represent the views of the Department of Veterans Affairs or the United States government. This manuscript is not under review elsewhere and the contents have not been part of any prior publication. All authors listed have contributed sufficiently to the project to be included as authors, and all those who are qualified to be authors are listed in the author byline; all authors have approved the submitted version of this manuscript.
}

Funding This study was supported by the Department of Veterans Affairs, Office of Research and Development, Health Services Research and Development Service (IIR 14-041).

\section{Compliance with Ethical Standards}

Conflict of interest All authors declares that they have conflict of intereset.

Ethical approval All procedures performed in studies involving human participants were in accordance with the ethical standards of the institutional and/or national research committee and with the 1964 Helsinki declaration and its later amendments or comparable ethical standards. This study was approved by the Institutional Review Boards at the Edward Hines Jr. VA Hospital and Edith Nourse Rogers Memorial Veterans Hospital.

\section{References}

Abrams, T. E., Vaughan-Sarrazin, M., \& Kaboli, P. J. (2010). Mortality and revascularization following admission for acute myocardial infarction: Implication for rural veterans. Journal of Rural Health, 26(4), 310-317. https://doi.org/10.1111/j.1748-0361.2010.00318 .x.

Albert, S. M., Agimi, Y., \& Martich, G. D. (2015). Interest in mental health care among patients making eVisits. The American Journal of Managed Care, 21(12), 867-872.

Berger, M., Wagner, T. H., \& Baker, L. C. (2005). Internet use and stigmatized illness. Social Science and Medicine, 61(8), 1821-1827. https://doi.org/10.1016/j.socscimed.2005.03.025.

Byerly, M. J., Nakonezny, P. A., \& Lescouflair, E. (2007). Antipsychotic medication adherence in schizophrenia. The Psychiatric Clinics of North America, 30(3), 437-452. https://doi. org/10.1016/j.psc.2007.04.002.

Carlson, K. F., Nelson, D., Orazem, R. J., Nugent, S., Cifu, D. X., \& Sayer, N. A. (2010). Psychiatric diagnoses among iraq and afghanistan war veterans screened for deployment-related traumatic brain injury. Journal of Traumatic Stress, 23(1), 17-24. https://doi.org/10.1002/jts.20483.

Cromer, R., Denneson, L. M., Pisciotta, M., Williams, H., Woods, S., \& Dobscha, S. K. (2017). Trust in mental health clinicians among patients who access clinical notes online. Psychiatric Services, 68(5), 520-523. https://doi.org/10.1176/appi.ps.201600168.

Cronin, R., Davis, S., Shenson, J., Chen, Q., Rosenbloom, S., \& Jackson, G. (2015). Growth of secure messaging through a patient portal as a form of outpatient interaction across clinical specialties. Applied Clinical Informatics, 6(02), 288-304. https://doi. org/10.4338/ACI2014-12-RA-0117.

Delbanco, T., Walker, J., Darer, J. D., Elmore, J. G., Feldman, H. J., Leveille, S. G., et al. (2010). Open notes: Doctors and patients signing on. Annals of Internal Medicine, 153(2), 121-125. https ://doi.org/10.7326/0003-4819-153-2-201007200-00008.

Denneson, L. M., Cromer, R., Williams, H. B., Pisciotta, M., \& Dobscha, S. K. (2017). A qualitative analysis of how online access to mental health notes is changing clinician perceptions of power and the therapeutic relationship. Journal of Medical Internet Research, 19(6), e208. https://doi.org/10.2196/jmir.6915.

Dobscha, S. K., Denneson, L. M., Jacobson, L. E., Williams, H. B., Cromer, R., \& Woods, S. (2016). VA mental health clinician experiences and attitudes toward OpenNotes. General Hospital Psychiatry, 38, 89-93. https://doi.org/10.1016/j.genhosppsy ch.2015.08.001.

Fischer, E. P., McCarthy, J. F., Ignacio, R. V., Blow, F. C., Barry, K. L., Hudson, T. J., et al. (2008). Longitudinal patterns of health system retention among veterans with schizophrenia or bipolar disorder. Community Mental Health Journal, 44(5), 321-330. https://doi. org/10.1007/s10597-008-9133-z. 
Fletcher, J., King, K., Christo, J., Machlin, A., Bassilios, B., Blashki, G., et al. (2014). An evaluation of an Australian initiative designed to improve interdisciplinary collaboration in primary mental health care. Evaluation and Program Planning, 45, 29-41. https ://doi.org/10.1016/j.evalprogplan.2014.03.002.

Goel, M. S., Brown, T. L., Williams, A., Hasnain-Wynia, R., Thompson, J. A., \& Baker, D. W. (2011). Disparities in enrollment and use of an electronic patient portal. Journal of General Internal Medicine, 26(10), 1112-1116. https://doi.org/10.1007/s1160 6-011-1728-3.

Gonzalez, A., Barinas, J., \& O'Cleirigh, C. (2011). Substance use: Impact on adherence and HIV medical treatment. Current HIV/ AIDS Reports, 8(4), 223-234. https://doi.org/10.1007/s1190 4-011-0093-5.

Greene, W. H. (1992). Econometric analysis (2nd ed.). London, UK: Macmillan Publishing Company.

Gundlapalli, A. V., Brignone, E., Divita, G., Jones, A. L., Redd, A., Suo, Y., et al. (2017). Using structured and unstructured data to refine estimates of military sexual trauma status among US military veterans. Studies in Health Technology and Informatics, 238, $128-131$

Haun, J. N., Lind, J. D., Shimada, S. L., Martin, T. L., Gosline, R. M., Antinori, N., et al. (2014). Evaluating user experiences of the secure messaging tool on the veterans affairs' patient portal system. Journal of Medical Internet Research, 16(3), e75. https ://doi.org/10.2196/jmir.2976.

Haun, J. N., Lind, J. D., Shimada, S. L., \& Simon, S. R. (2013). Evaluating secure messaging from the veteran perspective: Informing the adoption and sustained use of a patient- driven communication platform. Annals of Anthropological Practice, 37(2), 57-74. https ://doi.org/10.1111/napa.12029.

Hoge, C. W., Castro, C. A., Messer, S. C., McGurk, D., Cotting, D. I., \& Koffman, R. L. (2004). Combat duty in iraq and Afghanistan, mental health problems, and barriers to care. The New England Journal of Medicine, 351(1), 13-22. https://doi.org/10.1056/ NEJMoa040603.

Hyun, J. K., Pavao, J., \& Kimerling, R. (2009). Military sexual trauma. PTSD Research Quarterly, 20(2), 1-8.

Killaspy, H., Banerjee, S., King, M., \& Lloyd, M. (2000). Prospective controlled study of psychiatric out-patient non-attendance: Characteristics and outcome. The British Journal of Psychiatry, 176(2), 160-165.

Kipping, S., Stuckey, M. I., Hernandez, A., Nguyen, T., \& Riahi, S. (2016). A web-based patient portal for mental health care: Benefits evaluation. Journal of Medical Internet Research, 18(11), e294. https://doi.org/10.2196/jmir.6483.

Klein, D. M., Fix, G. M., Hogan, T. P., Simon, S. R., Nazi, K. M., \& Turvey, C. L. (2015). Use of the blue button online tool for sharing health information: Qualitative interviews with patients and providers. Journal of Medical Internet Research, 17(8), e199. https ://doi.org/10.2196/jmir.4595.

Kruse, C. S., Bolton, K., \& Freriks, G. (2015). The effect of patient portals on quality outcomes and its implications to meaningful use: A systematic review. Journal of Medical Internet Research, 17(2), e44. https://doi.org/10.2196/jmir.3171.

Lau, M., Campbell, H., Tang, T., Thompson, D. J., \& Elliott, T. (2014). Impact of patient use of an online patient portal on diabetes outcomes. Canadian Journal of Diabetes, 38(1), 17-21. https://doi. org/10.1016/j.jcjd.2013.10.005.

Lin, C.-T., Wittevrongel, L., Moore, L., Beaty, B. L., \& Ross, S. E. (2005). An internet-based patient-provider communication system: Randomized controlled trial. Journal of Medical Internet Research, 7(4), e47. https://doi.org/10.2196/jmir.7.4.e47.

Metraux, S., Clegg, L. X., Daigh, J. D., Culhane, D. P., \& Kane, V. (2013). Risk factors for becoming homeless among a cohort of veterans who served in the era of the Iraq and Afghanistan conflicts. American Journal of Public Health, 103(Suppl 2), S255-S261. https://doi.org/10.2105/AJPH.2013.301432.

Mitchell, A. J., \& Selmes, T. (2007). Why don't patients attend their appointments? Maintaining engagement with psychiatric services. Advances in Psychiatric Treatment, 13(6), 423-434.

Morgan, R. O., Petersen, L. A., Hasche, J. C., Davila, J. A., Byrne, M. M., Osemene, N. I., et al. (2009). VHA pharmacy use in veterans with medicare drug coverage. The American Journal of Managed Care, 15(3), e1-e8.

Myers, K. M., \& Lieberman, D. (2013). Telemental health: Responding to mandates for reform in primary healthcare. Telemedicine Journal and E-Health, 19(6), 438-443. https://doi.org/10.1089/ tmj.2013.0084.

Nazi, K. M. (2013). The personal health record paradox: Health care professionals' perspectives and the information ecology of personal health record systems in organizational and clinical settings. Journal of Medical Internet Research, 15(4), e70. https:// doi.org/10.2196/jmir.2443.

Nazi, K. M., Hogan, T. P., McInnes, D. K., Woods, S. S., \& Graham, G. (2013). Evaluating patient access to electronic health records: Results from a survey of veterans. Medical Care, 51(3 Suppl 1), S52-S56. https://doi.org/10.1097/MLR.0b013e31827808db.

Nazi, K. M., Hogan, T. P., Wagner, T., McInnes, D. K., Smith, B. M., Haggstrom, D., et al. (2010). Embracing a health services research perspective on personal health records: Lessons learned from the VA My HealtheVet system. Journal of General Internal Medicine, 25(1), 62-67.

Nazi, K. M., Turvey, C. L., Klein, D. M., \& Hogan, T. P. (2018). A decade of veteran voices: Examining patient portal enhancements through the lens of user-centered design. Journal of Medical Internet Research, 20(7), e10413. https://doi.org/10.2196/10413.

Otte-Trojel, T., de Bont, A., Rundall, T. G., \& van de Klundert, J. (2014). How outcomes are achieved through patient portals: A realist review. Journal of the American Medical Informatics Association, 21(4), 751-757. https://doi.org/10.1136/amiajnl-2013002501.

Pope, G. C., Kautter, J., Ellis, R. P., Ash, A. S., Ayanian, J. Z., Lezzoni, L. I., et al. (2004). Risk adjustment of medicare capitation payments using the CMS-HCC Model. Health Care Financing Review, 25(4), 119-141.

Sajatovic, M., Valenstein, M., Blow, F. C., Ganoczy, D., \& Ignacio, R. V. (2006). Treatment adherence with antipsychotic medications in bipolar disorder. Bipolar Disorders, 8(3), 232-241. https://doi. org/10.1111/j.1399-5618.2006.00314.x.

Sajatovic, M., Valenstein, M., Blow, F., Ganoczy, D., \& Ignacio, R. (2007). Treatment adherence with lithium and anticonvulsant medications among patients with bipolar disorder. Psychiatric Services, 58(6), 855-863. https://doi.org/10.1176/ ps.2007.58.6.855.

Sarkar, U., Lyles, C. R., Parker, M. M., Allen, J., Nguyen, R., Moffet, H. H., et al. (2014). Use of refill function through an online patient portal is associated with improved adherence to statins in an integrated health system. Medical Care, 52(3), 194-201. https ://doi.org/10.1097/MLR.0000000000000069.

Shimada, S. L., Allison, J. J., Rosen, A. K., Feng, H., \& Houston, T. K. (2016). Sustained use of patient portal features and improvements in diabetes physiological measures. Journal of Medical Internet Research, 18(7), e179. https://doi.org/10.2196/jmir.5663.

Shimada, S. L., Brandt, C. A., Feng, H., McInnes, D. K., Rao, S. R., Rothendler, J. A., et al. (2014). Personal health record reach in the veterans health administration: A cross-sectional analysis. Journal of Medical Internet Research, 16(12), e272. https://doi. org/10.2196/jmir.3751.

Simon, G. E., Beck, A., Rossom, R., Richards, J., Kirlin, B., King, D., et al. (2016). Population-Based outreach versus care as usual to prevent suicide attempt: Study protocol for a randomized 
controlled trial. Trials, 17(1), 452. https://doi.org/10.1186/s1306 3-016-1566-z.

Stecker, T., Fortney, J., Hamilton, F., Sherbourne, C. D., \& Ajzen, I. (2010). Engagement in mental health treatment among veterans returning from Iraq. Patient Preference and Adherence, 4, 45-49.

Stephenson, J. J., Tunceli, O., Gu, T., Eisenberg, D., Panish, J., Crivera, C., et al. (2012). Adherence to oral second-generation antipsychotic medications in patients with schizophrenia and bipolar disorder: Physicians' perceptions of adherence vs. pharmacy claims. International Journal of Clinical Practice, 66(6), 565-573. https ://doi.org/10.1111/j.1742-1241.2012.02918.x.

Swartz, M. S., Swanson, J. W., Hiday, V. A., Borum, R., Wagner, H. R., \& Burns, B. J. (1998). Violence and severe mental illness: The effects of substance abuse and nonadherence to medication. The American Journal of Psychiatry, 155(2), 226-231. https://doi. org/10.1176/ajp.155.2.226.

Talbot, F., Thériault, J., \& French, D. J. (2017). Self-compassion: Evaluation of a psychoeducational website. Behavioural and Cognitive Psychotherapy, 45(2), 198-203. https://doi.org/10.1017/S1352 465816000230.

Thomas, A. J., Eberly, L. E., Smith, G. D., Neaton, J. D., \& Multiple Risk Factor Intervention Trial (MRFIT) Research Group. (2006). ZIP-code-based versus tract-based income measures as long-term risk-adjusted mortality predictors. American Journal of Epidemiology, 164(6), 586-590. https://doi.org/10.1093/aje/kwj234.

Trivedi, R. B., Post, E. P., Sun, H., Pomerantz, A., Saxon, A. J., Piette, J. D., et al. (2015). Prevalence, comorbidity, and prognosis of mental health among US veterans. American Journal of Public Health, 105(12), 2564-2569. https://doi.org/10.2105/ AJPH.2015.302836.

Tsai, J., \& Rosenheck, R. A. (2012). Use of the internet and an online personal health record system by US veterans: Comparison of veterans affairs mental health service users and other veterans nationally. Journal of the American Medical Informatics Association, 19(6), 1089-1094. https://doi.org/10.1136/amiajnl-2012-000971.

Tsai, J., \& Rosenheck, R. A. (2015). Risk factors for homelessness among US veterans. Epidemiologic Reviews, 37, 177-195. https ://doi.org/10.1093/epirev/mxu004.

Turvey, C., Klein, D., Fix, G., Hogan, T. P., Woods, S., Simon, S. R., et al. (2014). Blue button use by patients to access and share health record information using the Department of Veterans Affairs' online patient portal. Journal of the American Medical Informatics Association, 21(4), 657-663. https://doi.org/10.1136/ amiajnl-2014-002723.

US Department of Veterans Affairs (VA). (2017). Women veterans health care: Facts and statistics about women veterans. Available at: https://www.womenshealth.va.gov/latestinformation/facts .asp. Accessed Apr 5, 2018.

US Department of Veterans Affairs. (2018a). Eligibility for VA health care. Retrieved from: https://www.va.gov/health-care/eligibility/. Accessed February 6, 2019.

US Department of Veterans Affairs. (2018b). My HealtheVet. Retrieved from: https://www.myhealth.va.gov/mhv-portal-web/home. Accessed Apr 12, 2018.

US Department of Veterans Affairs. (2018c). My HealtheVet: Statistics. Retrieved from: http://vaww.va.gov/MYHEALTHEVET/statistics .asp. Accessed Apr 12, 2018.

US Department of Veterans Affairs. (2019a). Veterans health administration: About VHA. Retrieved from: https://www.va.gov/healt h/aboutvha.asp. Accessed Feb 6, 2019.
US Department of Veterans Affairs. (2019b). Community care: information for veterans. Retrieved from: https://www.va.gov/ COMMUNITYCARE/programs/veterans/index.asp. Accessed Feb 6, 2019.

VA Information Resource Center (VIReC). (2011a). VIReC research user guide: Fiscal year 2009 VHA medical AS inpatient datasets. Hines IL: Department of Veterans Affairs, Health Services Research \& Development Service, VA Information Resource Center.

VA Information Resource Center (VIReC). (2011b). VIReC research user guide: Fiscal year 2009 VHA medical SAS outpatient datasets. Hines: Department of Veterans Affairs, Health Services Research \& Development Service, VA Information Resource Center.

VA Information Resource Center (VIReC). (2013). VIReC research user guide: VHA assistant deputy under secretary for health (ADUSH) enrollment files (2nd ed.). Hines IL: Department of Veterans Affairs, Health Services Research \& Development Service, VA Information Resource Center.

Velligan, D. I., Weiden, P. J., Sajatovic, M., Scott, J., Carpenter, D., Ross, R., et al. (2009). The expert consensus guideline series: Adherence problems in patients with serious and persistent mental illness. The Journal of Clinical Psychiatry, 70(Suppl 4), 1-46.

Wade-Vuturo, A. E., Mayberry, L. S., \& Osborn, C. Y. (2013). Secure messaging and diabetes management: Experiences and perspectives of patient portal users. Journal of the American Medical Informatics Association, 20(3), 519-525. https://doi.org/10.1136/ amiajnl-2012-001253.

Waitzkin, H., Cruz, M., Shuey, B., Smithers, D., Muncy, L., \& Noble, M. (2018). Military personnel who seek health and mental health services outside the military. Military Medicine, 183(5-6), e232e240. https://doi.org/10.1093/milmed/usx051.

Wallace, L. S., Angier, H., Huguet, N., Gaudino, J. A., Krist, A., Dearing, M., et al. (2016). Patterns of electronic portal use among vulnerable patients in a nationwide practice-based research network: From the OCHIN practice-based research network (PBRN). Journal of the American Board of Family Medicine, 29(5), 592-603. https://doi.org/10.3122/jabfm.2016.05.160046.

Wisco, B. E., Marx, B. P., Wolf, E. J., Miller, M. W., Southwick, S. M., \& Pietrzak, R. H. (2014). Posttraumatic stress disorder in the US veteran population: Results from the national health and resilience in veterans study. The Journal of Clinical Psychiatry, 75(12), 1338-1346. https://doi.org/10.4088/JCP.14m09328.

Wuerdeman, L., Volk, L., Pizziferri, L., Tsurikova, R., Harris, C., Feygin, R., . . Bates, D. W. (2005). How accurate is information that patients contribute to their electronic health record? AMIA annual symposium proceedings (pp. 834-838).

Yaeger, D., Himmelfarb, N., Cammack, A., \& Mintz, J. (2006). DSMIV diagnosed posttraumatic stress disorder in women veterans with and without military sexual trauma. Journal of General Internal Medicine, 21(Suppl 3), S65-S69. https://doi.org/10.11 11/j.1525-1497.2006.00377.x.

Publisher's Note Springer Nature remains neutral with regard to jurisdictional claims in published maps and institutional affiliations. 